\title{
Four Quadrants Transverse Abdominis Plane Block
}

National Cancer Institute

\section{Source}

National Cancer Institute. Four Quadrants Transverse Abdominis Plane Block. NCI

Thesaurus. Code C150576.

A peripheral nerve block that involves performing bilateral subcostal as well as posterior transverse abdominis plane blocks. 